\title{
Characterization of Regional Wind Patterns Using Self-Organizing Maps: Impact on Dallas-Fort Worth Long-Term Ozone Trends
}

\author{
Alexander Kotsakis, Yunsoo ChOI, And Amir H. SOURi \\ Department of Earth and Atmospheric Sciences, University of Houston, Houston, Texas \\ WONBAE JEON \\ Department of Earth and Atmospheric Sciences, University of Houston, Houston, Texas, and \\ Institute of Environmental Studies, Pusan National University, Pusan, South Korea \\ JAMES FLYNN \\ Department of Earth and Atmospheric Sciences, University of Houston, Houston, Texas
}

(Manuscript received 14 February 2018, in final form 2 February 2019)

\begin{abstract}
This study analyzes wind patterns in the Dallas-Fort Worth (DFW) area to gain a clearer understanding of meteorological patterns that have historically led to ozone exceedances in this region. Using a clustering algorithm called "self-organizing maps," we analyzed five notable characteristic regional wind patterns that occurred between April and October in 2000-14. A regional-scale high pressure system, cluster 2, produced weak southeast winds over DFW and accounted for $35.2 \%$ of ozone exceedances. Clusters 1 and 5 , characterized by southwesterly winds over the DFW area, were together associated with one-third of total ozone exceedances and show quantifiable impacts of the Barnett Shale region on downwind ozone production. Cluster 3, associated with Bermuda-high conditions, had relatively lower ozone in DFW (45.3 ppbv) resulting from transport of lower background ozone from the Gulf of Mexico. For clusters that produce southeasterly or southwesterly winds over Houston, ozone values in DFW were always larger than those in Houston. Further, to determine the potential impact of Houston pollution on DFW ozone, a sensitivity simulation with no Houston emissions and a base simulation were performed. The difference between the simulations revealed ozone enhancements of 1-2 ppbv and coincident enhancements in $\mathrm{NO}_{y}$ under south-southeasterly wind conditions. From these results, we conclude that downwind pollution from Houston and the Barnett Shale area exacerbates DFW ozone concentrations, underscoring the impacts of specific wind patterns on air quality in DFW.
\end{abstract}

\section{Introduction}

Tropospheric ozone not only acts as a potent greenhouse gas in the upper troposphere but also threatens vegetation and human health in the lower troposphere (Lefohn and Foley 1993). Ozone is photochemically produced in the presence of ultraviolet radiation through reactions between nitrogen oxides $\left(\mathrm{NO}_{x}\right)$ and volatile organic compounds (VOCs) emitted anthropogenically and biogenically. Regulations pertaining to ozone precursor emissions over the past 20 years have significantly decreased ozone concentrations in rural and urban areas. Cooper et al. (2012) analyzed the

Corresponding author: Yunsoo Choi, ychoi6@uh.edu 95th-, 50th-, and 5th-percentile ozone across the United States and found overall decreasing trends in rural and urban areas across the United States over the past 20 years. A related study by Simon et al. (2015) showed a decrease of $1-2$ ppbv yr $^{-1}$ in 95 th-percentile ozone during summer across the United States, the result of relative decreases in $\mathrm{NO}_{x}$ and VOCs. Comparable trends in 95th-, 50th-, and 5th-percentile ozone have also been observed despite increased emissions from Asia (Lin et al. 2017).

Similar trends have been observed over large cities in Texas, where decreases in $\mathrm{NO}_{x}$ and/or VOCs have led to long-term decreases in ozone levels (Choi and Souri 2015; Lefer et al. 2010). As a result, Dallas-Fort Worth (DFW) and Houston, Texas, subsequently experienced decreases in ozone exceedances between 2000 and 2015 . 
These decreasing trends are largely the result of stricter laws regulating the emission of ozone precursors contributing to the decrease in background levels of ozone (Suciu et al. 2017). While a majority of studies on ozone in Texas have concentrated on Houston, comparatively little work has examined the characteristic meteorological patterns and subsequent trends associated with ozone over DFW. This area is one of the fastest-growing cities in the United States and is the fifth-largest metropolitan area in the country. According to the 2015 U.S. Environmental Production Agency (EPA) 8-h ozone standard (https://www3.epa.gov/airquality/greenbook/ jnca.html\#Ozone_8-hr.2015.Dallas), DFW is classified as a moderate nonattainment area with a design value of 79 ppbv for 2017. Similar to Houston, the DFW region can be broken down into two ozone precursor emission regions. The urban DFW area is primarily a $\mathrm{NO}_{x}$-saturated environment with mobile emissions being the dominant emission source of $\mathrm{NO}_{x}$ and VOCs (Kim et al. 2011). West of DFW is a relatively VOC rich area that includes the Barnett Shale region, one of the largest natural gas extraction areas in the United States (Ahmadi and John 2015). This same study found that, starting in 2007, Barnett Shale gas production increased dramatically and corresponded to increased levels of ozone pollution downwind of the Barnett Shale over DFW. The interaction of ozone precursors with specific meteorological conditions can lead to ozone exceedances over the DFW region.

In one of the first studies to investigate the meteorological processes that result in conditions favorable for high-ozone days over DFW, McNider et al. (2005) found that the deformation of stationary fronts south of DFW caused a lack of dilution and a buildup of ozone along the weak convergence zone. Previous modeling studies have concluded that days with high ozone over DFW are influenced primarily by the intrastate transport of enhanced background ozone (Kemball-Cook et al. 2009; Kim et al. 2009; Pierce et al. 2009). While several of these studies have evaluated ozone background source regions, none have investigated characteristic wind patterns associated with distinct DFW ozone regimes and potential long-term changes in these wind patterns. Other studies that used clustering techniques to identify representative wind patterns with different ozone regimes have either covered short field campaign periods or have been focused on Houston (Banta et al. 2005; Darby 2005; Ngan and Byun 2011; Souri et al. 2016a).

This study identified the characteristic regional wind patterns associated with ozone variability over DFW and analyzed the associated long-term ozone trends. As compared with previous wind-pattern clustering studies, this study explored a different clustering algorithm that offers several advantages over other methods. We employed a chemical transport model to quantify any potential ozone enhancements over DFW resulting from the transport of ozone and ozone precursors from Houston. The results of this study provide a better understanding of the regional meteorological impact on air quality and provide a perspective on future air quality scenarios.

\section{Data and methods}

\section{a. Ozone and meteorological data}

We obtained ozone data from 24 Texas Commission on Environmental Quality continuous ambient monitoring stations (CAMS) located in a $28200-\mathrm{km}$ area centered over the DFW area (Fig. 1, right panel). The dataset also included stations outside the urban area, especially north of DFW, the location of the current design value site (Denton, Texas). For every station in the DFW domain, we calculated the maximum 8-h average (MDA8) ozone each day and then averaged the values from all of the stations, generating a single value for every day.

To evaluate the characteristic wind patterns, we analyzed North American Regional Reanalysis (NARR) $U$ and $V$ wind-component data, which have a horizontal grid spacing of approximately $32 \mathrm{~km}$ and temporal resolution of $3 \mathrm{~h}$. From the 29 available pressure levels, we selected $900 \mathrm{hPa}$ as a sufficient level for determining characteristic wind patterns over the southern United States from recent work by Souri et al. (2016a). Additionally, we tested all lower-tropospheric pressure levels and determined that $900 \mathrm{hPa}$ led to the most successful wind-pattern clustering. Evidence of successful clustering was the presence of multiple expected wind patterns such as the Bermuda high during the summer months and weak stagnant winds during the months with the most ozone exceedances. To capture the daytime variation in the wind, we used 3-hourly data covering only daytime photochemically active hours.

Additional NARR data variables used in this analysis were the daily mean 2-m temperature, downward shortwave radiation flux at the surface, and 2-m relative humidity. The NARR domain for these parameters was $3 \times 5$ grid cells that specifically covered the area where CAMS are located across DFW. For every day of this analysis, we calculated the domain mean for each of these parameters. The CAMS and NARR data covered April to October (3150 days) from 2000 to 2014 (15 years). Specifically, for the analysis of longterm ozone trends over DFW, the CAMS data coverage was expanded to include data from 2015 and 2016. 

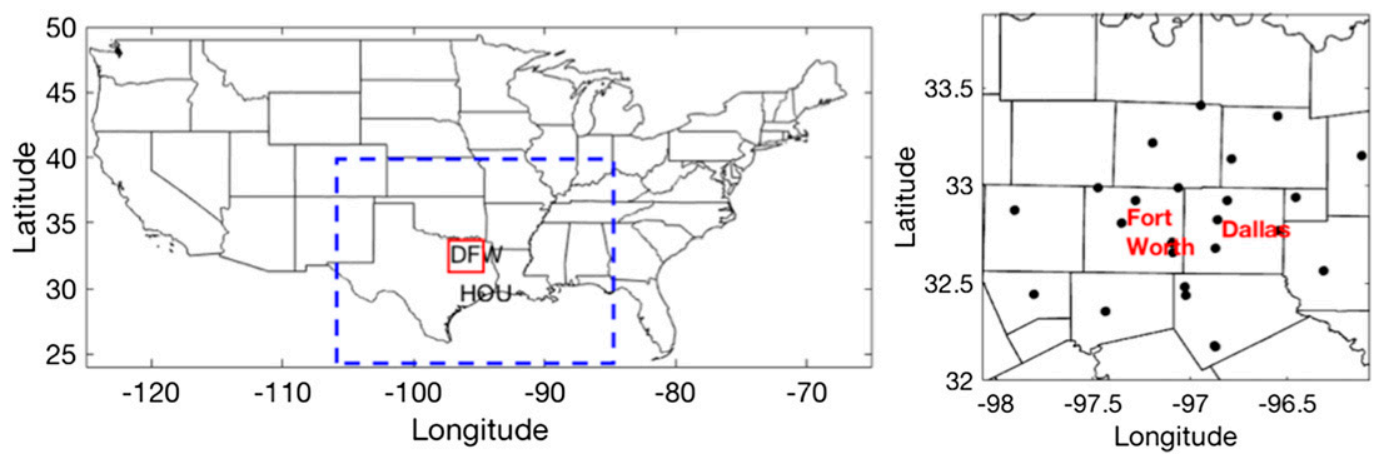

FIG. 1. (left) The regional domain used for clustering (blue) and the domain over DFW (red) for CAMS data used for ozone analysis. HOU indicates the Houston area. (right) Zoomed-in view of DFW showing the individual CAMS stations.

The month range used in this study was determined from the annual distribution of ozone exceedances. Additional information about the seasonal distribution of ozone exceedances appears in the results section.

\section{b. Self-organizing-maps clustering}

Self-organizing maps (SOM) is an artificial neural network algorithm that is trained using unsupervised learning. Developed by Kohonen (2001), SOM is one of the most widely used clustering algorithms, along with $k$ means. As compared with $k$ means, in which cluster centroids are independent, SOM allows the neurons or clusters to move topologically on an $n$-dimensional grid. The movement of neurons is performed by a built-in neighborhood function that determines the distance between the neurons responsible for neuron interactions. The neighbor-weighted distance between the neurons allows for neurons to be combined on the basis of their similarity to (distance from) each other. The code used to perform SOM clustering is from the SOM Toolbox, available from MATLAB (Vesanto et al. 2000). SOM has been implemented in a number of previous meteorological and atmospheric chemistry studies (Glisan et al. 2016; Katurji et al. 2015; Pearce et al. 2011; Stauffer et al. 2016).

For SOM clustering, this study used $U$ and $V$ wind data as inputs and incorporated an $81 \times 81$ gridcell domain covering Texas, Oklahoma, Louisiana, Arkansas, Alabama, Mississippi, western Tennessee, southern Kansas, Missouri, and Illinois (Fig. 1, left). To reduce redundancy in the data, we performed principal components analysis (PCA) on the $U$ and $V$ data prior to inputting them into the SOM algorithm and then used the output components from the PCA as inputs into SOM. Before running SOM, we defined the dimensions of the neurons, whose products represented the number of clusters observed in the output of SOM. Although the dimension size (or the number of clusters) is fixed, the neighborhood distances (or distances between clusters) allowed clusters to be combined.

\section{c. Model setup}

This study utilized the EPA's Community Multiscale Air Quality (CMAQ) model, version 5.0.2 (Byun and Schere 2006), to simulate ozone over DFW. This same model has been used by previous studies to investigate air quality issues over Houston (Byun et al. 2007; Czader et al. 2015; Diao et al. 2016a; Li et al. 2016; Pan et al. 2015; Souri et al. 2016b). We compiled anthropogenic emissions from the EPA's National Emission Inventory (NEI) for 2011 and prepared the modeling using the Sparse Matrix Operator Kernel Emissions Modeling System (SMOKE), version 3.6 (Houyoux et al. 2000). We obtained meteorological inputs using the Weather Research and Forecasting (WRF) Model, version 3.7 (Skamarock and Klemp 2008), and extracted biomass-burning emissions from the Fire Inventory from the National Center for Atmospheric Research (FINN, version 1.5; Wiedinmyer et al. 2011). Since the inventory was not provided for the CMAQ chemical mechanism, the FINN Model for Ozone and Related Chemical Tracers, version 4 (MOZART-4), mechanism was mapped onto Carbon Bond Mechanism 2005/Aerosol Module 2006 (CB05/ AERO6). The model used motor vehicle emissions inputs from the EPA Motor Vehicle Emissions Simulator (MOVES) model, and the domain was mapped over the contiguous United States with a coverage of $459 \times 299$ grid cells at $12-\mathrm{km}$ grid spacing.

\section{Results and discussion}

\section{a. Monthly exceedance distribution and long-term ozone trends}

In this section, the monthly distribution of ozone exceedances and long-term trends for ozone over DFW is presented 

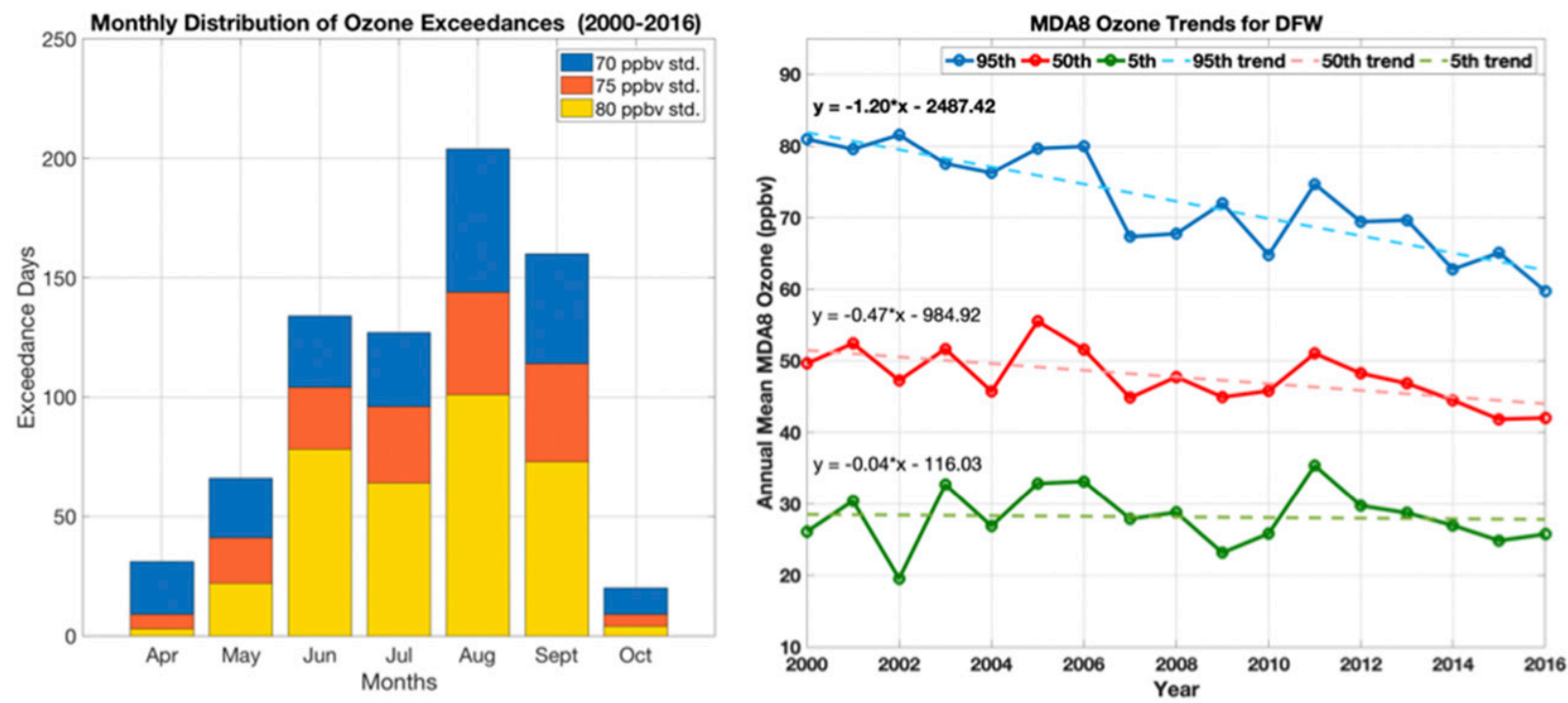

FIG. 2. (left) A monthly distribution of ozone exceedances over DFW for 70-, 75-, and 80-ppbv MDA8 standards from 2000 to 2016. (right) Long-term trends in DFW MDA8 ozone for the 95th, 50th, and 5th percentiles from 2000 to 2016. Trends that were determined to be statistically significant have their corresponding equation shown in boldface type.

prior to discussing the results of the wind-pattern analysis. The monthly distribution of ozone exceedances for each MDA8 ozone standard from 2000 to 2016 is shown in Fig. 2 (left panel). For all of the standards, exceedances steadily increased from April to June, but in July the number of exceedances decreased for all of the standards relative to the previous month. This decrease in ozone exceedances in July has been well documented in previous studies, which have attributed this finding to the location and strength of the Bermuda high transporting relatively clean air from the Gulf of Mexico into the southern plains during the summer months (Choi and Souri 2015; Wang et al. 2016; Zhu and Liang 2013). The majority of ozone exceedances occurred in August and September when meteorological conditions were optimal for efficient ozone production.

On the basis of the results of the analysis of the seasonal distribution of ozone exceedances, we included April and October in the wind-pattern analysis to capture the full distribution of ozone exceedances. We analyzed 95th-, 50th-, and 5th-percentile MDA8 ozone for each year and fit a linear trend (Fig. 2, right panel) to evaluate the long-term trends for DFW. Beginning in 2000, all of the percentiles exhibited downward trends, with the 95th-percentile MDA8 decreasing at a statistically significant rate of $1.20 \mathrm{ppbv} \mathrm{yr}^{-1}$. The overall decreasing trend in MDA8 ozone was primarily the result of the decreasing emissions of ozone precursors (Choi and Souri 2015). We analyzed wind-pattern clusters to determine the different meteorological patterns and their associated ozone regimes over DFW.

\section{b. Clusters and their characteristics}

To identify distinct wind clusters, we tested multiple configurations of the principal components and dimensions of SOM - a combination of 4-60 principal components and 6-36 neurons-to find the combination that achieved the optimal amount of variance (at least $>80 \%$ ). At 200 epochs with a constant learning rate, we tested SOM under multiple neuron configurations and selected dimensions of $5 \times 5$ ( 25 neurons) because they produced the largest amount of variability between the clusters. After running multiple iterations using these dimensions, SOM generated a neighborweighted distance output; this is one of the benefits of SOM. It allowed for the further manual combination of neurons on the basis of the neighbor-weighted distance with a smaller neighbor-weighted distance between neurons, indicating that they more closely resembled one another, and vice versa. The combinations of neurons (clusters), determined by their topological relationships, formed 11 wind-pattern clusters from which we calculated statistics relating to frequency, ozone, and meteorological conditions. The remainder of this paper focuses on five of these wind-pattern clusters (Table 1). (The remaining six clusters, not shown here, appear in Fig. A1 in the appendix with their statistics.) The wind patterns and spatial ozone observations of these five clusters are plotted in Fig. 3 with a description of each below. The long-term ozone 
TABLE 1. Frequency and chemical characteristics for each cluster over DFW for 2000-14 (standard deviations are in parentheses). Boldface values indicate the maximum for the variable.

\begin{tabular}{|c|c|c|c|c|c|}
\hline Clusters & Cluster 1 & Cluster 2 & Cluster 3 & Cluster 4 & Cluster 5 \\
\hline Occurrences $n$ & 486 & 513 & 726 & 420 & 319 \\
\hline Frequency $(\%)$ & 15.4 & 16.2 & 23.2 & 13.3 & 10.1 \\
\hline Exceedances (MDA8 $>70$ ppbv) & 138 & 303 & 142 & 71 & 142 \\
\hline Exceedances per cluster occurrence (\%) & 28.4 & 59.0 & 19.6 & 16.9 & 44.5 \\
\hline Exceedance percentage $(\%)$ & 16.0 & 35.2 & 16.5 & 8.2 & 16.5 \\
\hline DFW CAMS avg MDA8 ozone (ppbv) & $50.2(14)$ & $\mathbf{6 0 . 7}(13)$ & $45.3(13)$ & $44.4(14)$ & $55.5(14)$ \\
\hline Max MDA8 ozone (ppbv) & 114.9 & 127.9 & 121.6 & 117 & 119.5 \\
\hline 5th-percentile MDA8 (ppbv) & 29.9 & 37.0 & 27.5 & 23.5 & 33.0 \\
\hline Mean 2-m temperature $\left({ }^{\circ} \mathrm{C}\right)$ & $33.3(5.3)$ & $32.7(6.0)$ & $35.3(4.7)$ & $29.0(6.7)$ & $33.7(6.4)$ \\
\hline $\begin{array}{l}\text { Mean downward shortwave } \\
\text { radiation flux }\left(\mathrm{Wm}^{-2}\right)\end{array}$ & $289.4(64.6)$ & $296.2(61.9)$ & $\mathbf{3 1 1 . 8}(56.5)$ & $260.6(75.2)$ & $307.5(59.5)$ \\
\hline Mean RH (\%) & $59.6(13.6)$ & $55.4(13.1)$ & $58.8(12.6)$ & $66.9(12.2)$ & $56.9(13.9)$ \\
\hline
\end{tabular}

trends for each cluster are plotted in Fig. 4, and the monthly frequency distributions for each cluster are plotted in Fig. 5.

\section{1) Cluster 1}

Cluster $\mathrm{C} 1$ represented a wind pattern with southerly and southwesterly winds over DFW with relatively clean marine air transported into the eastern half of Texas because of the fetch from the Gulf of Mexico. The orientation of this wind pattern was due to the placement of a synoptic-scale high pressure system that was located over the southeastern United States. During the 15-yr study period, this cluster occurred $15.4 \%$ of the time, accounted for $16.0 \%$ of the total ozone exceedances, and had exceedances $28.4 \%$ of the time it occurred. The station plot (located below the wind-pattern plot in Fig. 3) indicates that the ozone was relatively higher in the northern and northeastern part of the domain, which was the result of southwesterly winds transporting VOCs from the Barnett Shale area and $\mathrm{NO}_{x}$ from urban DFW downwind to produce ozone. While the effects of Barnett Shale VOCs on ozone might be incremental (Rutter et al. 2015) relative to urban DFW, previous work has suggested that the transport of VOCs from the Barnett Shale area plays an important role in ozone variability across DFW (Ahmadi and John 2015). The associated long-term ozone trends showed statistically significant decreases at the 95th percentile resulting from the aforementioned decreases in ozone precursor emissions (Fig. 4). In an analysis of the seasonal occurrence of this cluster, $\mathrm{C} 1$ occurred most often during autumn (September and October).

\section{2) Cluster 2}

Cluster $\mathrm{C} 2$ was associated with weak, stagnant conditions over the eastern half of Texas caused by a weak high pressure system located over Arkansas and Oklahoma. This pattern was associated with weak easterly and southeasterly winds over the DFW area. On the basis of this wind pattern, a lack of dilution and the favorable transport of $\mathrm{NO}_{x}$ and VOCs (from DFW and Barnett, respectively) led to efficient ozone production over north and northwest DFW. The air transported into DFW by this wind pattern contained relatively higher continental background ozone, which in addition to local production led to a larger number of exceedances than noted with any other cluster. Numerous studies have shown that efficient ozone production by local sources coincides with days in which enhanced regional background ozone is present under these wind-pattern conditions (Blanchard et al. 2008; Kemball-Cook et al. 2009; Pierce et al. 2009). Using the 5th percentile of MDA8 ozone as a proxy for background ozone, $\mathrm{C} 2$ had the highest 5th-percentile MDA 8 ozone value of 37.0 ppbv. Statistically, during the 15-yr study period, this cluster also exhibited the highest CAMS MDA8 ozone in DFW (referred to as "DFW CAMS MDA8 ozone"), 60.7 ppbv, with exceedances $59.2 \%$ of the time it occurred. Although the expectation is that the combination of the highest temperatures and largest downward incoming shortwave radiation would be associated with the highest DFW CAMS MDA8 ozone, this was not the case. This cluster was associated with the second-lowest mean 2-m temperature and third-lowest downward shortwave radiation flux, underscoring the importance of wind speed and direction to ozone variability over DFW. Long-term trends in MDA8 ozone revealed statistically significant negative trends in the 95th-percentile ozone and mean ozone as well as the largest negative trend in 5th-percentile ozone despite it being statistically insignificant. On a seasonal basis, C2 occurred most frequently in August and September, 

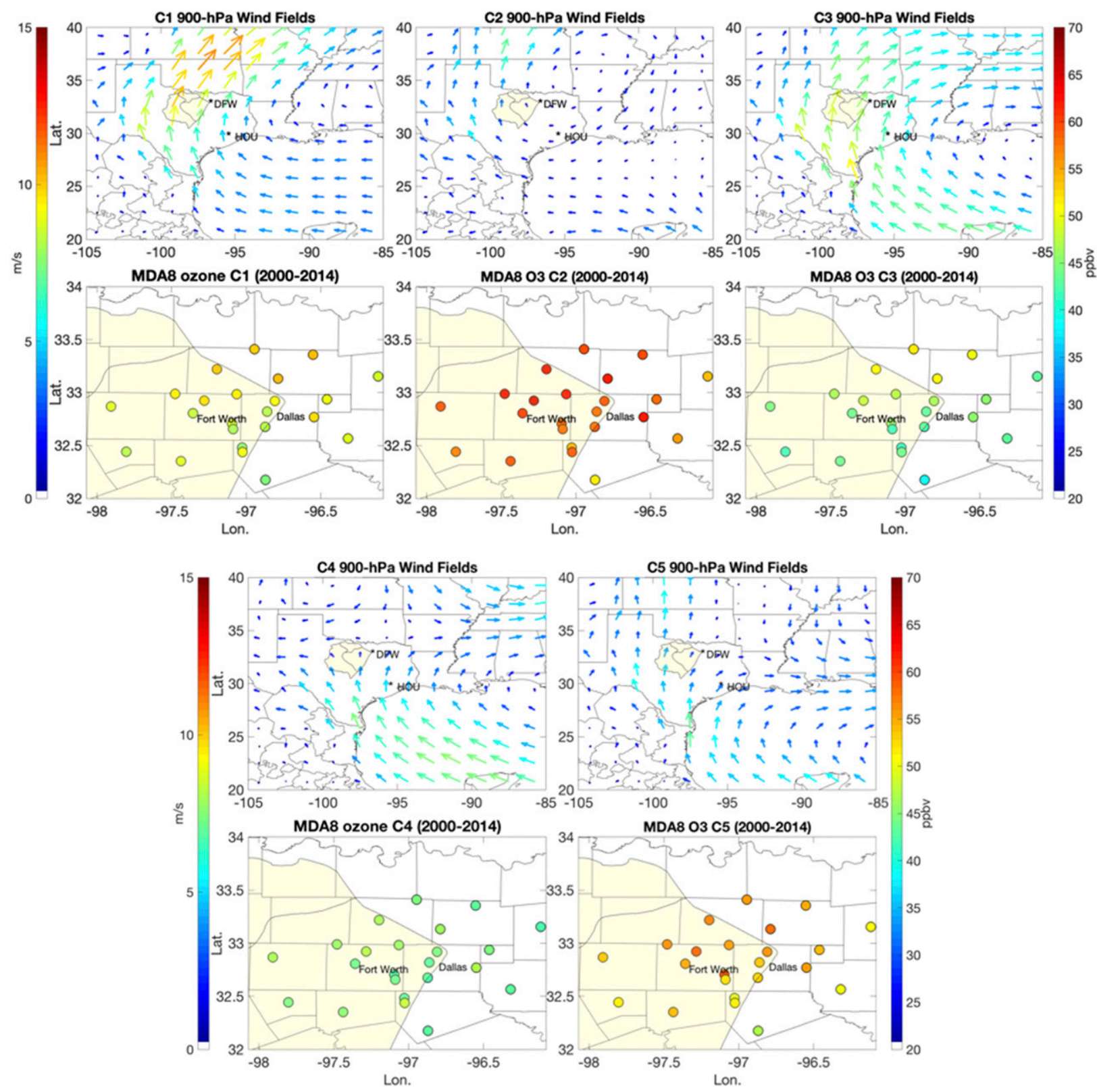

FIG. 3. Each pair of stacked plots indicates meteorological and chemical conditions for each cluster (C1-C5). The top panel of each pair shows mean 900-hPa wind fields from NARR for clusters $1-5$, and the bottom panels show the corresponding surface MDA8 ozone from CAMS over DFW for 2000-14. The yellow shaded area is the location of the Barnett Shale.

months with the highest number of ozone exceedances (Fig. 2).

\section{3) Cluster 3}

Cluster C3 was associated with a moderately strong high pressure system located over the northeastern Gulf of Mexico. Relatively clean marine air was transported into this region from the Gulf of Mexico triggered by a synoptic feature called the Bermuda high. The positioning of this high pressure system resulted in strong southerly and southwesterly winds over the northeastern half of Texas, including DFW. The influence of the Bermuda high was strongest during the summer months (June-August) and peaked during July (Fig. 5). This coincided with the aforementioned decrease in ozone exceedances in July relative to the previous month (Fig. 2). The westward extension of the Bermuda high decreases background ozone values over Texas (Wang et al. 2016) but increases ozone over the eastern United States (Shen et al. 2015). Although similar to the pattern 


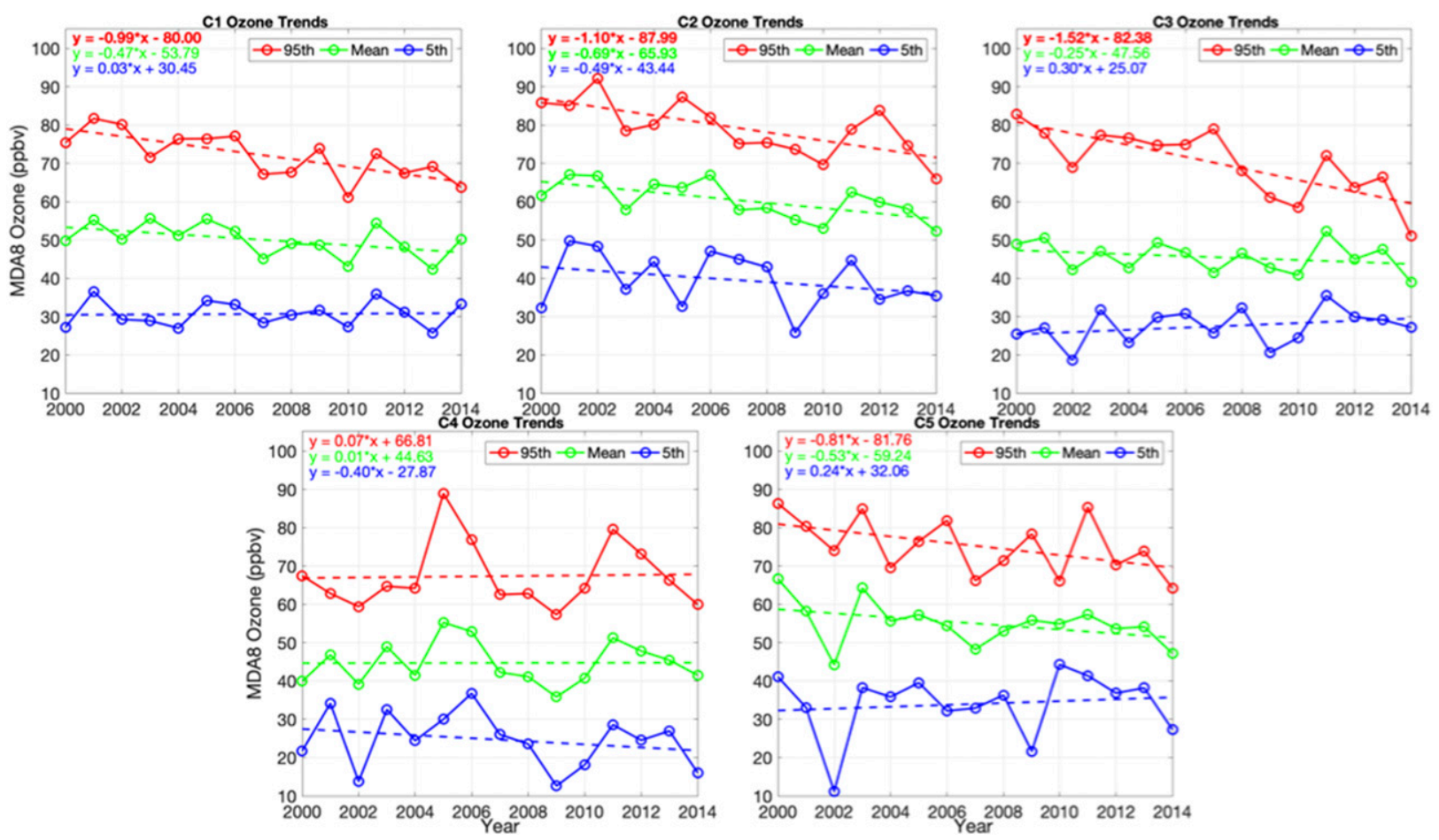

FIG. 4. Annual 95th-percentile, mean, and 5th-percentile MDA8 ozone from 2000 to 2014 for DFW for each cluster (solid lines). A linear fit is applied to all metrics for each cluster (dashed lines), with their corresponding equations listed in each panel. Trends that were determined to be statistically significant have their corresponding equation boldfaced.

of $\mathrm{C} 1, \mathrm{C} 3$ had a larger wind velocity. In the station plot of $\mathrm{C} 3$, we observed a gradient in ozone that was also similar to that in $\mathrm{C} 1$, but the ozone values were smaller because of its increased wind speed and dilution. This cluster occurred the most often with a frequency of $23.2 \%$, contributed to $16.5 \%$ of total exceedance days, and had exceedances $19.6 \%$ of the time it occurred. Interestingly, this cluster was associated with the highest DFW domain mean 2-m temperature and the secondhighest downward incoming shortwave radiation flux, which coincided with this cluster occurring primarily during the summer months. However, because of the transport of relatively low background ozone from the Gulf of Mexico, this cluster had the second-lowest DFW CAMS MDA8 ozone. Despite long-term MDA8 ozone trends showing the largest statistically significant decrease in 95th-percentile ozone when compared with all other clusters, the 5th-percentile ozone showed the largest positive trend even though it was not statistically significant. It is not clear if this increasing background ozone was from Houston pollution or from enhanced background pollution from development in the Barnett Shale region.

\section{4) Cluster 4}

Cluster C4 was associated with a stationary, weak cold front draped across northern Texas. The southern half of Texas featured south-southeasterly winds while the northern half featured north-northeasterly winds. This area of convergence likely had cloud cover and precipitation, which hindered ozone production. This was confirmed by this cluster having the lowest mean downward shortwave radiation flux and the highest relative humidity. This cluster occurred $13.3 \%$ of the time and had exceedances $16.9 \%$ of the time it occurred. It occurred most often at the beginning of spring, decreased in frequency during summer, and slightly increased in frequency in autumn with the return of cold fronts through DFW.

\section{5) Cluster 5}

Cluster C5 was associated with a wind pattern that produced weak southwest winds over DFW. A broad high pressure system located over Florida led to weak southwesterly flow over the eastern half of Texas with winds becoming weaker as they moved into northern Texas. The primary reason for the weak/stagnant winds was the lack of a pressure gradient over the central and southern plains. Depending on the direction of the winds, the Barnett Shale region potentially played a role in downwind ozone production over DFW. In 2007, Barnett Shale gas production increased dramatically, changing levels of ozone pollution. This change was the 


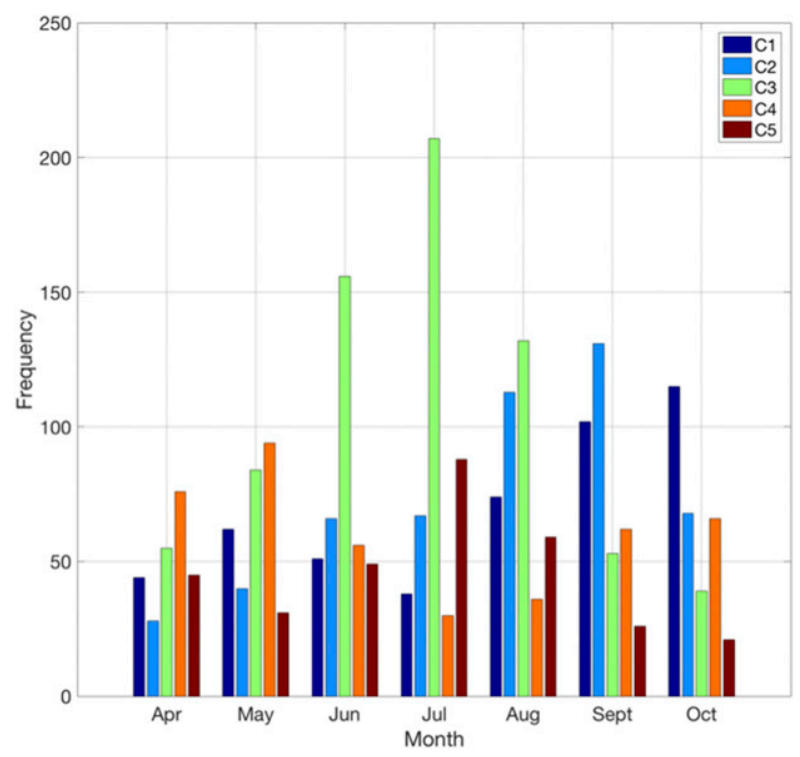

FIG. 5. Monthly distribution of cumulative occurrences for each cluster (C1-C5) from 2000 to 2014 for DFW.

motivation for a study by Ahmadi and John (2015), who concluded that areas downwind of shale gas regions (defined as the Barnett Shale area) incurred positive changes in the minimum value, 1 st-percentile, and 10th-percentile ozone ranging from 0.4 to 5.2 ppbv between the periods of 2006-07 and 2007-13. Although the 5th-percentile MDA8 ozone trend was not statistically significant for this cluster, the 5th-percentile ozone increased by 3.8 ppbv from 2000 to 2014 . This value was within the range of values reported by Ahmadi and John (2015) and further confirms the impact of the Barnett Shale on baseline ozone. This cluster, with a DFW CAMS MDA8 ozone value of 55.5 ppbv, produced the second-highest number of exceedances (142) (tied with C3) and exceeded $44.5 \%$ of the time it occurred. The combination of VOC sources from the Barnett Shale region and the urban DFW emissions led to efficient ozone production and ozone exceedances downwind over northern and northeastern DFW. In addition, this cluster had the second-highest DFW domain mean 2-m temperature and second-highest mean downward shortwave radiation flux, which facilitated efficient ozone production. This cluster occurred most frequently during the summer months from June to August.

\section{c. Comparison with Houston}

The clustering results indicated that the highest ozone concentrations over DFW occurred under the influence of weak regional-scale high pressure over eastern Texas and the lower Mississippi valley. The pattern observed in this study is similar to the wind pattern associated with the highest ozone over Houston (Ngan and Byun 2011; Souri et al. 2016a). We calculated MDA8 ozone for each cluster with Houston CAMS data and the results of the calculation indicated that the cluster associated with the highest ozone in DFW (C2) was also associated with the highest ozone in Houston (Fig. 6). Owing to the regional-scale high pressure in $\mathrm{C} 2$ over Houston and DFW, the wind direction was favorable for the transport of ozone precursors from local emission sources and continental background ozone. As previously mentioned in the description of $\mathrm{C} 2,5$ th percentile ozone was highest with this cluster indicating relatively higher background levels than those of other clusters. In addition, the weak wind speeds associated with this pattern led to a lack of dilution of ozone and its precursors. Under Bermuda-high conditions (C3), the difference between DFW and Houston was the second largest at 10.5 ppbv. This disparity was likely driven by relatively clean air transported into Houston from the Gulf of Mexico, while pollutants transported from Houston to DFW enhanced DFW ozone concentrations. Furthermore, to investigate the cause of this difference and to determine the potential impacts of Houston pollution downwind on DFW during clusters with south-southeasterly or south-southwesterly flow, we ran model sensitivity simulations.

\section{d. Impact of Houston pollution transport}

Multiple wind patterns featured southeasterly, southerly, and southwesterly winds over the eastern half of Texas. Under these meteorological conditions, ozone precursors emitted and produced by Houston were transported north toward DFW. A previous study by Senff et al. (2010) found that pollution transported from Houston could raise concentrations of background ozone by as much as $10 \mathrm{ppbv}$. We hypothesized, therefore, that the enhanced background ozone from Houston could be transported into the DFW area. Two CMAQ simulations were run to determine the impact of Houston pollution on DFW ozone during these wind-pattern conditions. The first was the "base" case with normal model settings. For the sensitivity simulation, we turned off the emissions over the Houston domain. Both of these simulations covered a 90-day period from 1 June 2014 to 30 August 2014, and the MDA8 ozone was calculated over the model domain for each day of the base simulation and the corresponding time for the "no emissions" simulation. Note that both the cluster analysis and the meteorological model simulation used the same NARR wind data, which allowed for a coherent comparison between the model and the clustering results. The model-measurement comparison yielded a correlation of 0.81 , indicating the satisfactory 


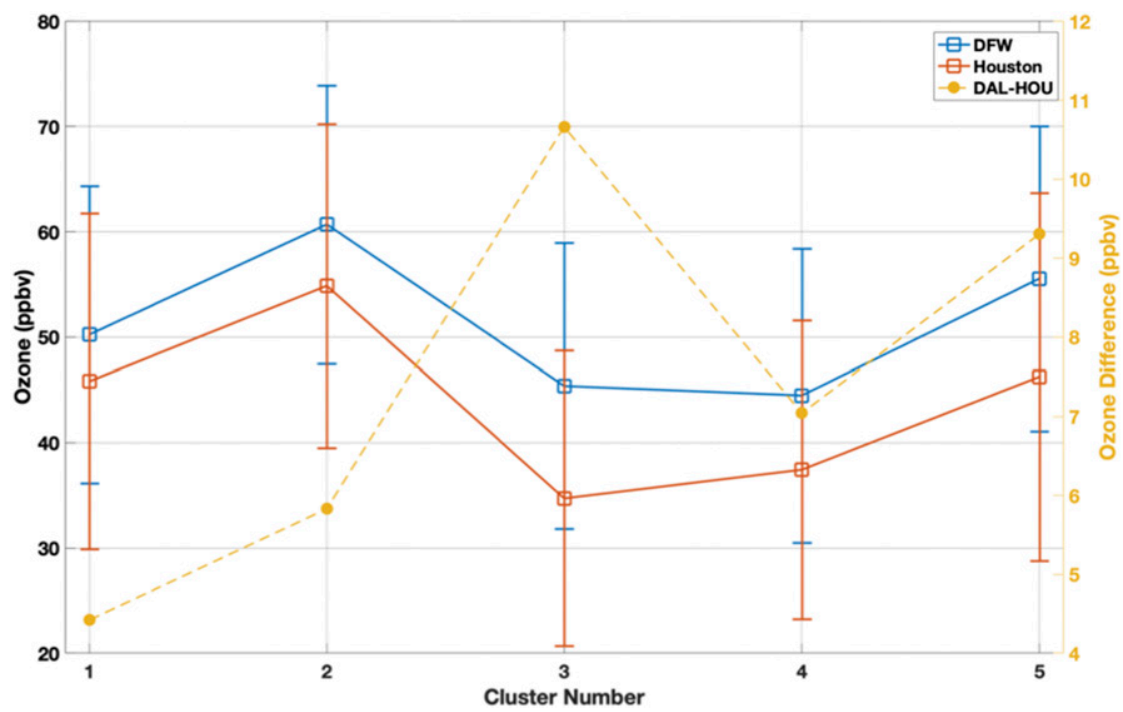

FIG. 6. CAMS MDA8 ozone over DFW (blue) and Houston (red) for each cluster for 200014. Standard deviation is indicated by the vertical bars for each data point. Also shown is the difference between DFW (DAL) and Houston for averaged ozone for 2000-14 (dashed yellow).

performance of the base model simulation during this period despite the documented underestimation of $\mathrm{NO}_{x}$ emissions in the 2011 National Emissions Inventory (Travis et al. 2016). From the days in which each cluster occurred during the 90-day period, the corresponding daily model outputs were placed into their respective cluster bins. We then compared the two simulations by calculating the difference in ozone between the two simulations to determine if Houston pollution increased background ozone advected to DFW. If the difference between the two cases was above zero, we concluded that Houston pollution raised background ozone concentrations transported into DFW. The cluster occurrences during the model period are listed in Table 2.

We identified several quantifiable impacts on DFW ozone from transported Houston pollution under various wind patterns by comparing the two runs (Fig. 7, top). In addition, we calculated mean 72-h HYSPLIT back trajectories for each of these clusters (Stein et al. 2015), binned the daily trajectories into each cluster according to its frequency of occurrence, and averaged them to obtain one mean trajectory per cluster (Fig. 7, bottom). Cluster 2, while having a mean trajectory originating from Louisiana and the southern Mississippi valley, had numerous individual trajectories pass over the Houston area. This corresponded to an $\sim 2$-ppbv enhancement caused by Houston pollution under cluster- 2 conditions. Clusters 1 and 3, which featured southeasterly flow over Houston to progressively southwesterly flow over DFW, showed a 1-1.5-ppbv enhancement in ozone over DFW from
Houston pollution. Both of these clusters on individual days had modeled ozone enhancements up to $8 \mathrm{ppbv}$, which is within the range of observed enhancements by Senff et al. (2010). Since C3, associated with the Bermuda high, had the highest frequency of all of the clusters, the contribution of Houston downwind to DFW was an impactful finding. These results provide new quantitative insights on the contribution of Houston pollution downwind on DFW ozone under Bermuda-high conditions.

To strengthen our understanding of the transport of ozone precursors from Houston, we analyzed the differences in simulated total reactive nitrogen $\left(\mathrm{NO}_{y}\right)$ in DFW. Acting as a $\mathrm{NO}_{x}$ reservoir, $\mathrm{NO}_{y}$ can be transported long distances and affect ozone production downwind. We calculated the mean daily $\mathrm{NO}_{y}$ for both simulations and the difference between the two simulations. In line with the previous analysis of ozone from the sensitivity simulations, we found coincident enhancements in $\mathrm{NO}_{y}$ that could be attributed to the transport of Houston pollution to DFW (Fig. 8). Enhancements in $\mathrm{NO}_{y}$ ranged from 0.2 to $1 \mathrm{ppbv}$, depending on the cluster. The analysis of $\mathrm{NO}_{y}$ provided further evidence of the transport of Houston pollution downwind and its contribution to ozone chemistry over DFW. From the comparison of

TABLE 2. The number of occurrences of the clusters during the model-simulated period (2014 summer).

\begin{tabular}{cccccc}
\hline \hline Clusters & $\mathrm{C} 1$ & $\mathrm{C} 2$ & $\mathrm{C} 3$ & $\mathrm{C} 4$ & $\mathrm{C} 5$ \\
\hline$n$ & 9 & 14 & 35 & 7 & 16 \\
\hline
\end{tabular}



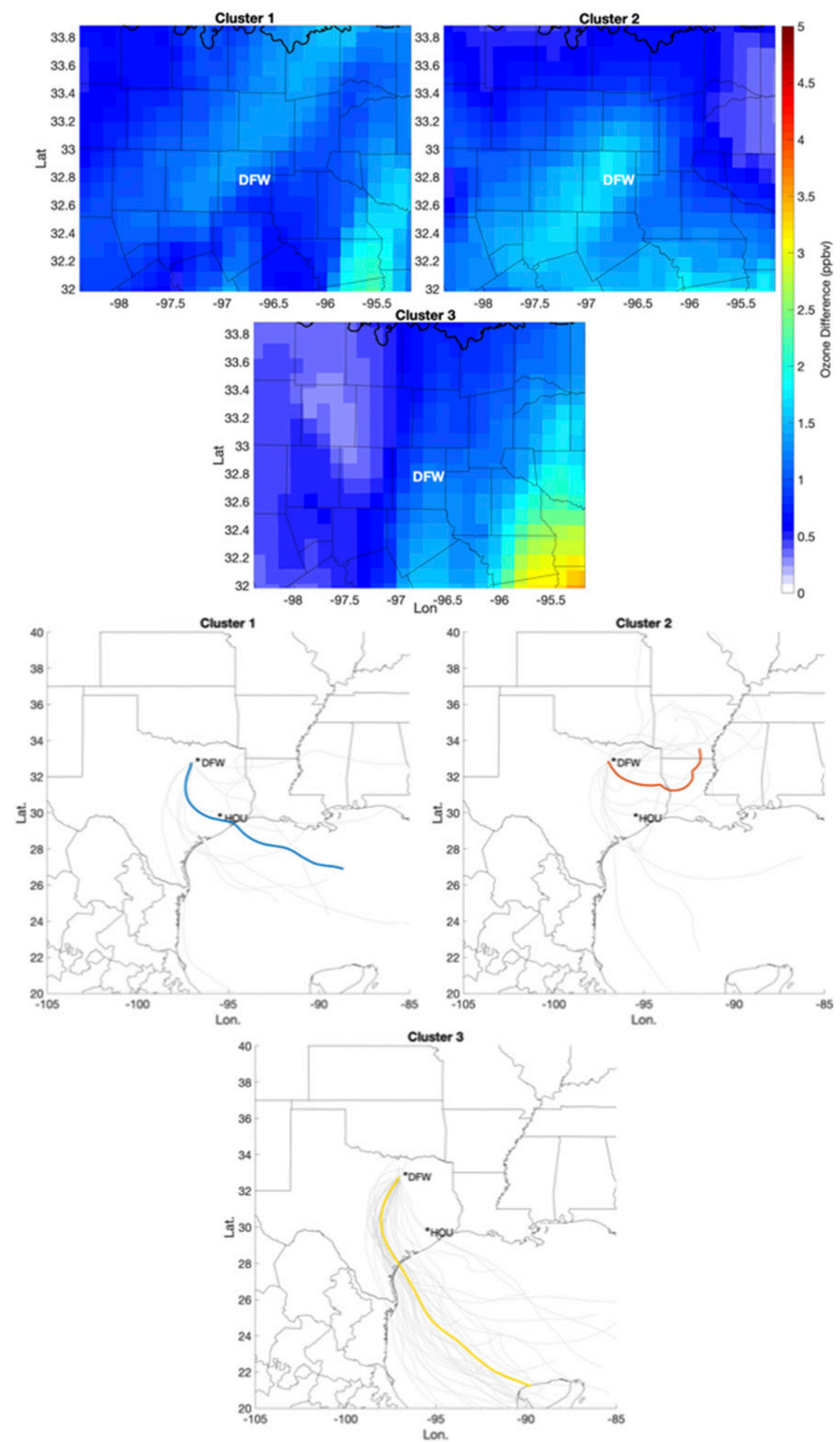

FIG. 7. (top) Difference between the ozone concentrations of the base and no-Houstonemissions CMAQ simulations for $\mathrm{C} 1, \mathrm{C} 2$, and $\mathrm{C} 3$ cluster days. (bottom) Mean 72-h back trajectories for each of the featured clusters, with all of the trajectories within the cluster plotted in light gray. 


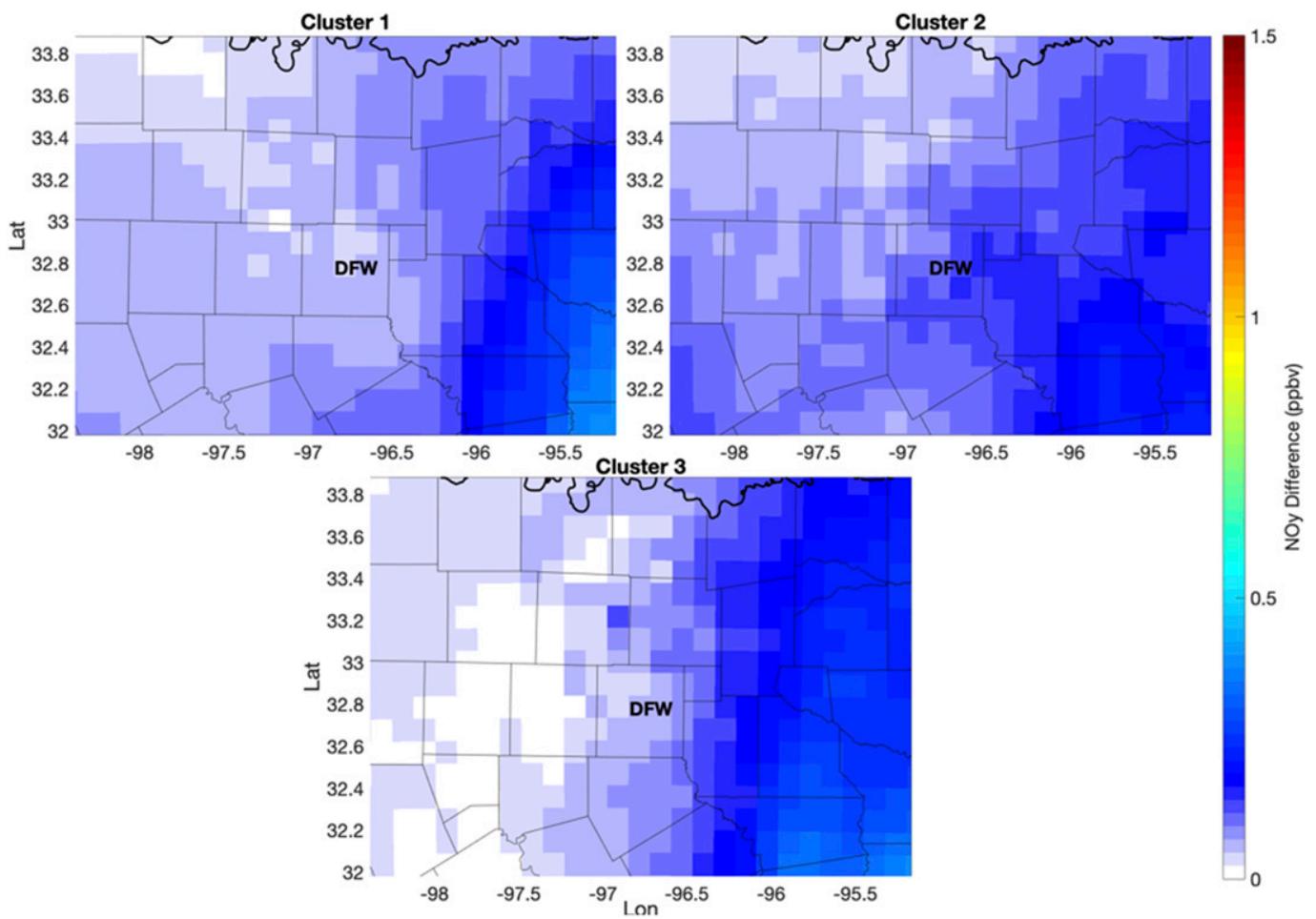

FIG. 8. Difference between the reactive nitrogen $\left(\mathrm{NO}_{y}\right)$ concentrations of the base and no-Houston-emissions CMAQ simulations for $\mathrm{C} 1, \mathrm{C} 2$, and $\mathrm{C} 3$ cluster days.

these two model simulations, we concluded that DFW could experience ozone enhancements as high as $5 \mathrm{ppbv}$ from ozone precursors originating in Houston.

\section{Conclusions}

This study provided a long-term analysis of regional wind patterns and associated ozone variability over DFW. We clustered 15 years (2000-14) of gridded windcomponent data from NARR and used self-organizing maps to determine characteristic wind patterns. We used surface ozone data over DFW covering the same period to analyze the variability of ozone under various wind-pattern conditions, the seasonal distribution of ozone exceedances, and long-term trends in ozone. For the analysis of wind patterns and ozone, we selected the months of April-October on the basis of data about the seasonal distribution of ozone exceedances and found decreasing trends in 95th-, 50th-, and 5th-percentile MDA8 ozone largely as a result of decreasing ozone precursor emissions. Since no previous studies had evaluated longterm changes in meteorological conditions in relation to Dallas ozone trends, we calculated MDA8 ozone and longterm ozone trends for each wind-pattern cluster.

During the analysis of 3150 days, we identified 11 wind-pattern clusters, 5 of which captured the largest percentage of total days. The five clusters exhibited the following wind characteristics and percentage contribution to the total ozone exceedance days for DFW: $\mathrm{C} 1$ (moderate southwesterly wind; $16 \%$ ), C2 (weak to stagnant southeasterly wind; 35.2\%), C3 (moderate southwesterly wind; $16.5 \%$ ), C4 (weak southwesterly wind along a frontal zone; $8.2 \%$ ), and C5 (weak to stagnant southwesterly wind; $16.5 \%$ ).

The wind pattern associated with the largest amount of ozone exceedances was $\mathrm{C} 2$, which featured a weak regional-scale high pressure system that resulted in weak southeasterly wind conditions over DFW. The transport of relatively higher continental background ozone from the lower Mississippi valley, combined with the favorable transport of local ozone precursors from DFW, resulted in the largest percentage of high-ozone days $(35.2 \%)$ and the highest MDA8 ozone (60.7 \pm 13 ppbv). Other clusters that resulted in days with ozone exceedances included $\mathrm{C} 1$ and $\mathrm{C} 5$, which featured similar weak southwesterly winds over DFW and demonstrated the potential impact of the Barnett Shale region on downwind ozone production. The 5th-percentile MDA8 ozone trend was statistically insignificant for C5 from 2000 to 2014. However, over those 15 years the 5th-percentile ozone increased by 3.8 ppbv, which was within the range reported in a previous study that 
quantified the impact of the Barnett Shale on DFW ozone. The combination of VOC sources from the Barnett Shale region and urban DFW emissions, led to efficient ozone production and ozone exceedances downwind over northern and northeastern DFW.

We compared ozone data from Houston and DFW to determine regional similarities in ozone concentrations for all of the wind-pattern clusters. Under $\mathrm{C} 2$ conditions, both DFW and Houston observed the highest average ozone concentrations. During Bermuda-high conditions (C3), the difference between DFW and Houston was the second largest at 10.5 ppbv. Two model simulations were run to determine if pollution transported from Houston to DFW affected ozone concentrations over DFW under any of the wind-pattern conditions. Differences between the results of the simulations indicated that the transport of pollution from Houston contributed to ozone enhancements over the DFW area. Mean ozone enhancements for clusters 1 and 3 ranged from 1 to 2 ppbv in DFW with individual days experiencing up to an 8 ppbv contribution from pollution transported from Houston. More notably, this study was the first to quantify the enhancement of ozone over DFW under Bermuda-high conditions (C3), building on previous work that investigated the regional and national impact of the Bermuda high on ozone concentrations. Interestingly, while $\mathrm{C} 3$ showed the largest decreasing trend in 95th-percentile ozone, it also showed the largest positive but statistically insignificant, trend in 5th-percentile ozone, highlighting the impact that areas upwind of DFW can have on background ozone.

The analysis of $\mathrm{NO}_{y}$ for the same clusters revealed coincident enhancements in $\mathrm{NO}_{y}$, which provided further evidence of the transport of Houston pollution to DFW. Compliance with current and future ozone attainment requirements set forth by the EPA require accurate quantification of the magnitude of the impact from major emission locations such as Houston. This study focused only on the downwind impact of ozone and ozone precursors from Houston on ozone levels over DFW from strictly a meteorological perspective; however, a critical aspect when attempting to decrease ozone pollution is the determination of source apportionment. Additional work is also needed to evaluate how photochemical regimes in areas between urban centers (Houston, Dallas, Austin, etc.) have changed because of decreases in $\mathrm{NO}_{x}$ and VOCs. In future work, we plan to quantify the impact of other sources such as biomass burning on incoming background ozone and particulate matter into DFW to determine if those impacts are more significant during particular years.

Acknowledgments. We thank the Texas Commission on Environmental Quality for providing the air quality data used in this study and the NOAA/ESRL Physical Sciences Division in Boulder, Colorado, for providing the data (https://www.esrl.noaa.gov/psd/data/gridded/ data.narr.html). This study is partially supported by the National Strategic Project-Fine particle of the National Research Foundation of Korea (NRF) funded by the Ministry of Science and ICT (MSIT), the Ministry of Environment (ME), and the Ministry of Health and Welfare(MOHW) (NRF-2017M3D8A1092022).

\section{APPENDIX}

\section{Description of Clusters 6-11}

The wind patterns and spatial ozone observations of these six clusters are plotted in Fig. A1 with a description of each below, and the corresponding statistics are shown in Table A1. The statistics described in each cluster section are in comparison with the 11 total clusters.

\section{a. Cluster 6}

Cluster C6 was a post-cold-front pattern with a high pressure located over central Texas. This pattern featured moderate northwest winds, which transported relatively high background ozone into the region from rural and urban sources in the plains and the eastern Rockies. This pattern was also associated with the lowest DFW domain mean 2-m temperature and relative humidity, which was expected since air behind cold fronts is typically drier and cooler. Relatively higher ozone was observed in southern and southeast side of DFW, indicating the northwesterly winds transported local ozone precursor emissions along with regional background ozone. This wind pattern had a DFW CAMS MDA 8 ozone value of 49.9 ppbv and exceeded $12.6 \%$ of the time it occurred. During the 15 -yr study period, the frequency of this cluster increased 0.56 days $\mathrm{yr}^{-1}$, a statistically significant trend. The result of the increased frequency of this wind pattern was the increase in the number of days impacted by relatively higher continental background ozone. The amount of continental background ozone advected into an area on top of locally influenced ozone production can affect whether an area is in or out of compliance with the ozone standard. Interestingly, the 5th percentile of the DFW CAMS MDA8 ozone values for this cluster had the second-highest ozone value of $35.0 \mathrm{ppbv}$. This relatively higher background value, with the addition of locally produced ozone, led to ozone exceedances in this region under favorable wind patterns for ozone production that occurred after C6. This cluster most commonly appeared in April, May, and October, when 

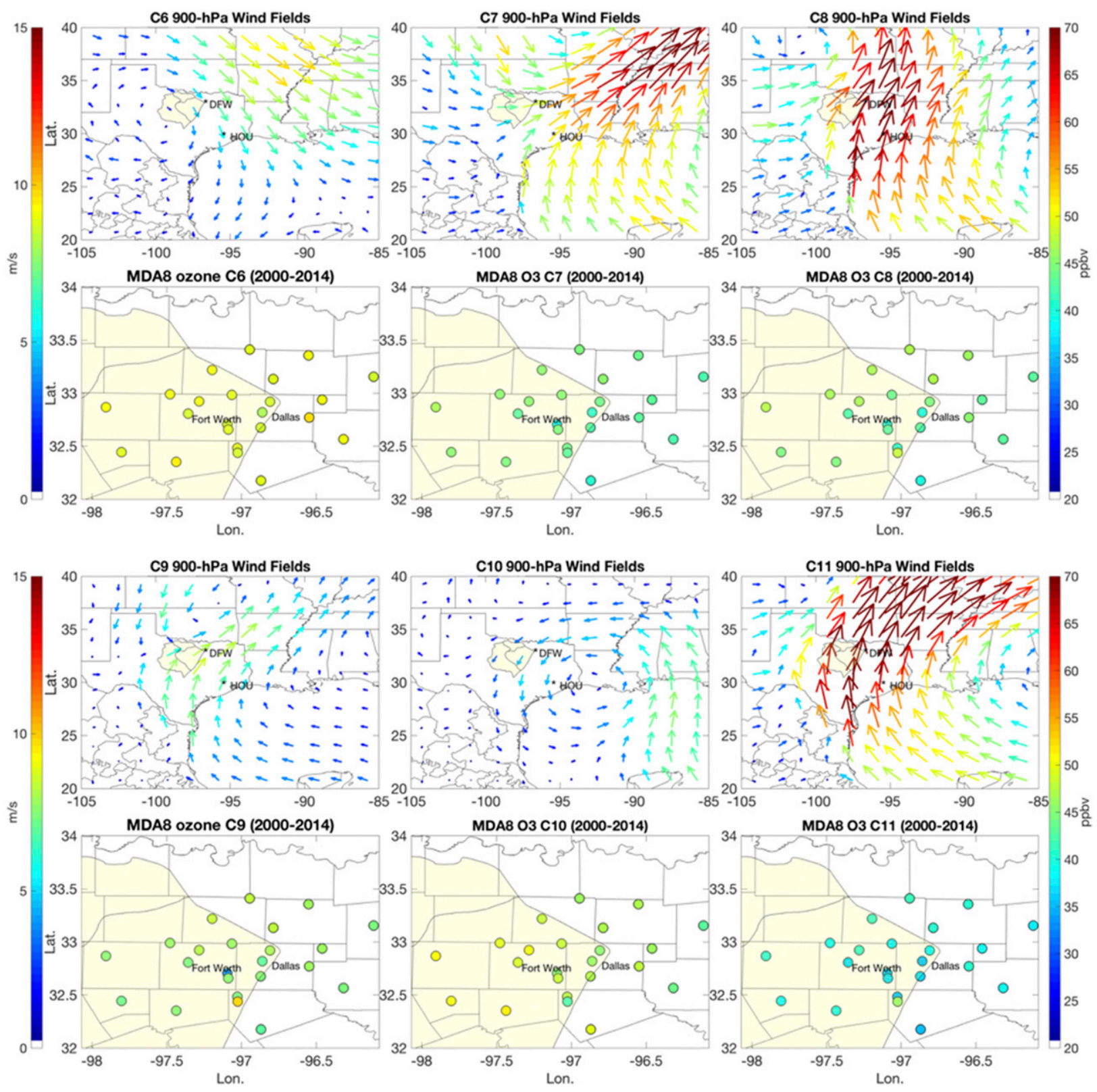

FIG. A1. As in Fig. 3, but for clusters C6-C11.

cold fronts had enough energy to push far south to DFW.

\section{b. Cluster 7}

Cluster C7 was a wind pattern that showed a strong cold front over DFW, indicated by strong convergence over the region. The strong southwesterly winds south of DFW and strong winds northwest of DFW indicated that this was a frontal zone. Since fronts were associated with higher wind speeds and cloudy conditions, this cluster inefficiently produced ozone. This was confirmed by the mean downward shortwave radiation flux of this cluster being the fourth lowest. This cluster occurred $3.8 \%$ of the time and was associated with the second-lowest DFW CAMS MDA8 ozone value of 43.6 ppbv. During the $15-y r$ study period, the frequency of this cluster did not change significantly. Similar to cluster 6 , this cluster was most common during the months when the jet stream was progressive and cold fronts associated with low pressure systems had enough energy to push south to DFW. 
TABLE A1. Frequency and chemical characteristics for clusters 6-11 over DFW for 2000-14 (standard deviations are given in parentheses).

\begin{tabular}{lcccccc}
\hline \multicolumn{1}{c}{ Clusters } & Cluster 6 & Cluster 7 & Cluster 8 & Cluster 9 & Cluster 10 & Cluster 11 \\
\hline Occurrences $n$ & 143 & 120 & 67 & 106 & 113 & 137 \\
Frequency (\%) & 4.5 & 3.8 & 2.1 & 3.3 & 3.5 & 4.3 \\
Exceedances (MDA8 > 70 ppbv) & 18 & 1 & 4 & 16 & 24 & 2 \\
Exceedances per cluster occurrence (\%) & 12.6 & 0.8 & 5.9 & 15.0 & 21.2 & 1.4 \\
Exceedance percentage (\%) & 2.1 & 0.1 & 0.5 & 1.9 & 2.8 & 0.2 \\
DFW CAMS avg MDA8 ozone (ppbv) & $49.9(9)$ & $43.6(9)$ & $44.2(9)$ & $45.6(13)$ & $47.8(13)$ & $38.7(7)$ \\
Max MDA8 ozone (ppbv) & 89.4 & 99.5 & 99.2 & 101.4 & 98.6 & 103.3 \\
5th-percentile MDA8 (ppbv) & 35.0 & 26.9 & 31.8 & 26.2 & 26.5 & 26.5 \\
Mean 2-m temperature ( ${ }^{\circ}$ C) & $25.0(5.4)$ & $28.5(6.7)$ & $31.6(3.9)$ & $31.3(6.1)$ & $28.4(7.0)$ & $33.0(4.4)$ \\
Mean downward shortwave radiation & $300.6(60.5)$ & $285.3(64.7)$ & $306.2(51.9)$ & $265.3(67.0)$ & $249.2(75.8)$ & $320.0(53.7)$ \\
$\quad$ flux (Wm ${ }^{-2}$ ) & & & & & $65.6(14.4)$ & $68.9(9.7)$ \\
Mean RH $(\%)$ & $54.5(10.5)$ & $66.7(10.7)$ & $72.4(7.7)$ & $64.2(13.7)$ & $65.6(9.7)$ \\
\hline
\end{tabular}

\section{c. Cluster 8}

Cluster C8 was a wind pattern that exhibited pre-coldfront conditions. Very strong southerly winds ahead of the cold front led to relatively lower ozone values over DFW because of dilution, relatively lower background ozone from the Gulf of Mexico, and a strong likelihood of clouds and precipitation. Consequently, this cluster had the highest DFW domain mean relative humidity. It also occurred with the lowest frequency, occurring only $2.1 \%$ of the time. Similar to C7, C8 exhibited no longterm change in frequency. This cluster appeared most frequently in April and May for the same reasons as described in C6 and C7.

\section{d. Cluster 9}

Cluster C9 was associated with a weak front and a synoptic low located over central Oklahoma and a broad high pressure located over the southeastern United States, leading to moderate southwesterly winds over DFW and throughout southeastern Texas. This pattern led to relatively low occurrence of ozone exceedances, stemming from dilution and likely cloud cover. This cluster occurred $3.4 \%$ of the time, and there were exceedances $15 \%$ of the time it occurred. This cluster occurred most frequently during September and October.

\section{e. Cluster 10}

C10 was a unique cluster since it is characteristic of the tropical lows in the Gulf of Mexico. A similar pattern was observed in previous studies that investigated wind patterns over Texas (Davis et al. 1998; Souri et al. 2016a). This pattern led to extensive cloud cover and subsequent precipitation, confirmed by this cluster having the lowest mean downward shortwave radiation flux, which was indicative of substantial cloud cover. Although this cluster had the fifth-highest mean relative humidity, it produced the largest standard deviation that exceeded the highest mean relative humidity value. This cluster contained some elevated ozone because of the relatively persistent transport of higher background ozone into the DFW area. This cluster occurred $3.5 \%$ of the time, and there were exceedances $21.2 \%$ of the time it occurred. This cluster, exhibiting a slightly positive trend during the 15-yr study period, occurred most often in September and October, corresponding to the near peak of the Atlantic Ocean hurricane season.

\section{f. Cluster 11}

C11 was the wind pattern with the strongest winds over DFW and throughout the eastern half of Texas, caused by a strong pressure gradient between the central plains region and the Gulf of Mexico. This cluster, which occurred $4.3 \%$ of the time, was associated with the lowest DFW CAMS MDA8 ozone of 38.7 ppbv. Although this cluster had the highest mean downward shortwave radiation flux, which indicated efficient ozone photochemistry, the dilution effects of the strong wind speeds were dominant. For reasons similar to those described in $\mathrm{C} 6-\mathrm{C} 8$, this cluster most frequently occurred in April and May.

\section{REFERENCES}

Ahmadi, M., and K. John, 2015: Statistical evaluation of the impact of shale gas activities on ozone pollution in north Texas. Sci. Total Environ., 536, 457-467, https://doi.org/10.1016/ j.scitotenv.2015.06.114

Banta, R. M., and Coauthors, 2005: A bad air day in Houston. Bull. Amer. Meteor. Soc., 86, 657-669, https://doi.org/ 10.1175/BAMS-86-5-657.

Blanchard, C. L., S. Tanenbaum, and D. R. Lawson, 2008: Differences between weekday and weekend air pollutant levels in Atlanta; Baltimore; Chicago; Dallas-Fort Worth; Denver; Houston; New York; Phoenix; Washington, DC; and surrounding areas. J. Air Waste Manag. Assoc., 58, 1598-1615, https://doi.org/ 10.3155/1047-3289.58.12.1598. 
Byun, D., and K. L. Schere, 2006: Review of the governing equations, computational algorithms, and other components of the Models-3 Community Multiscale Air Quality (CMAQ) modeling system. Appl. Mech. Rev., 59, 51-77, https://doi.org/ 10.1115/1.2128636.

Byun, D. W., S. T. Kim, and S. B. Kim, 2007: Evaluation of air quality models for the simulation of a high ozone episode in the Houston metropolitan area. Atmos. Environ., 41, 837-853, https://doi.org/10.1016/j.atmosenv.2006.08.038.

Choi, Y., and A. H. Souri, 2015: Chemical condition and surface ozone in large cities of Texas during the last decade: Observational evidence from OMI, CAMS, and model analysis. Remote Sens. Environ., 168, 90-101, https://doi.org/10.1016/j.rse.2015.06.026.

Cooper, O. R., R. S. Gao, D. Tarasick, T. Leblanc, and C. Sweeney, 2012: Long-term ozone trends at rural ozone monitoring sites across the United States, 1990-2010. J. Geophys. Res., 117, D22307, https://doi.org/10.1029/2012JD018261.

Czader, B. H., Y. Choi, X. Li, S. Alvarez, and B. Lefer, 2015: Impact of updated traffic emissions on HONO mixing ratios simulated for urban site in Houston, Texas. Atmos. Chem. Phys., 15, 1253 1263, https://doi.org/10.5194/acp-15-1253-2015.

Darby, L. S., 2005: Cluster analysis of surface winds in Houston, Texas, and the impact of wind patterns on ozone. J. Appl. Meteor., 44, 1788-1806, https://doi.org/10.1175/JAM2320.1.

Davis, J. M., B. K. Eder, D. Nychka, and Q. Yang, 1998: Modeling the effects of meteorology on ozone in Houston using cluster analysis and generalized additive models. Atmos. Environ., 32, 2505-2520, https://doi.org/10.1016/S1352-2310(98)00008-9.

Diao, L., A. Roy, B. Czader, S. Pan, W. Jeon, A. H. Souri, and Y. Choi, 2016a: Modeling the effect of relative humidity on nitrous acid formation in the Houston area. Atmos. Environ., 131, 78-82, https://doi.org/10.1016/j.atmosenv.2016.01.053.

Glisan, J. M., W. J. Gutowski Jr., J. J. Cassano, E. N. Cassano, and M. W. Seefeldt, 2016: Analysis of WRF extreme daily precipitation over Alaska using self-organizing maps. J. Geophys. Res. Atmos., 121, 7746-7761, https://doi.org/ 10.1002/2016JD024822.

Houyoux, M. R., J. M. Vukovich, C. J. Coats, N. J. M. Wheeler, and P. S. Kasibhatla, 2000: Emission inventory development and processing for the Seasonal Model for Regional Air Quality (SMRAQ) project. J. Geophys. Res., 105, 9079-9090, https:// doi.org/10.1029/1999JD900975.

Katurji, M., B. Noonan, P. Zawar-Reza, T. Schulmann, and A. Sturman, 2015: Characteristics of the springtime alpine valley atmospheric boundary layer using self-organizing maps. J. Appl. Meteor. Climatol., 54, 2077-2085, https://doi.org/ 10.1175/JAMC-D-14-0317.1.

Kemball-Cook, S., D. Parrish, T. Ryerson, U. Nopmongcol, J. Johnson, E. Tai, and G. Yarwood, 2009: Contributions of regional transport and local sources to ozone exceedances in Houston and Dallas: Comparison of results from a photochemical grid model to aircraft and surface measurements. J. Geophys. Res., 114, D00F02, https://doi.org/ 10.1029/2008JD010248.

Kim, S., D. W. Byun, and D. Cohan, 2009: Contributions of interand intra-state emissions to ozone over Dallas-Fort Worth, Texas. Civ. Eng. Environ. Syst., 26, 103-116, https://doi.org/ 10.1080/10286600802005364.

Kim, S.-W., and Coauthors, 2011: Evaluations of $\mathrm{NO}_{x}$ and highly reactive VOC emission inventories in Texas and their implications for ozone plume simulations during the Texas Air Quality Study 2006. Atmos. Chem. Phys., 11, 11361-11386, https://doi.org/10.5194/acp-11-11361-2011.
Kohonen, T., 2001: Self-Organizing Maps. 3rd ed. Springer, 501 pp.

Lefer, B., B. Rappengluck, J. Flynn, and C. Haman, 2010: Photochemical and meteorological relationships during the Texas-II Radical and Aerosol Measurement Project (TRAMP). Atmos. Environ., 44, 4005-4013, https://doi.org/10.1016/j.atmosenv.2010.03.011.

Lefohn, A. S., and J. K. Foley, 1993: Establishing relevant ozone standards to protect vegetation and human health: Exposure dose/response considerations. J. Air Waste Manage. Assoc., 43, 106-112, https://doi.org/10.1080/1073161X.1993.10467111.

Li, X., Y. Choi, B. Czader, A. Roy, H. Kim, B. Lefer, and S. Pan, 2016: The impact of observation nudging on simulated meteorology and ozone concentrations during DISCOVER-AQ 2013 Texas campaign. Atmos. Chem. Phys., 16, 3127-3144, https://doi.org/10.5194/acp-16-3127-2016.

Lin, M., L. W. Horowitz, R. Payton, A. M. Fiore, and G. Tonnesen, 2017: US surface ozone trends and extremes from 1980 to 2014: Quantifying the roles of rising Asian emissions, domestic controls, wildfires, and climate. Atmos. Chem. Phys., 17, 2943 2970, https://doi.org/10.5194/acp-17-2943-2017.

McNider, R. T., K. Doty, W. B. Norris, and A. Biazar, 2005: Conceptual model for extreme ozone concentration events in Dallas and east Texas based on reduced dilution in frontal zones. Texas Commission on Environmental Quality Rep. Project H12.8HRA, 12, 53 pp.

Ngan, F., and D. Byun, 2011: Classification of weather patterns and associated trajectories of high-ozone episodes in the Houston-Galveston-Brazoria area during the 2005/06 TexAQS-II. J. Appl. Meteor. Climatol., 50, 485-499, https:// doi.org/10.1175/2010JAMC2483.1.

Pan, S., Y. Choi, A. Roy, X. Li, W. Jeon, and A. H. Souri, 2015: Modeling the uncertainty of several VOC and its impact on simulated VOC and ozone in Houston, Texas. Atmos. Environ., 120, 404-416, https://doi.org/10.1016/j.atmosenv.2015.09.029.

Pearce, J. L., J. Beringer, N. Nicholls, R. J. Hyndman, P. Uotila, and N. J. Tapper, 2011: Investigating the influence of synopticscale meteorology on air quality using self-organizing maps and generalized additive modeling. Atmos. Environ., 45, 128136, https://doi.org/10.1016/j.atmosenv.2010.09.032.

Pierce, R. B., and Coauthors, 2009: Impacts of background ozone production on Houston and Dallas, Texas, air quality during the Second Texas Air Quality Study field mission. J. Geophys. Res., 114, D00F09, https://doi.org/10.1029/2008JD011337.

Rutter, A. P., R. J. Griffin, B. K. Cevik, K. M. Shakya, L. Gong, S. Kim, J. H. Flynn, and B. L. Lefer, 2015: Sources of air pollution in a region of oil and gas exploration downwind of a large city. Atmos. Environ., 120, 89-99, https://doi.org/10.1016/ j.atmosenv.2015.08.073.

Senff, C. J., R. J. Alvarez, R. M. Hardesty, R. M. Banta, and A. O. Langford, 2010: Airborne lidar measurements of ozone flux downwind of Houston and Dallas. J. Geophys. Res., 115, D20307, https://doi.org/10.1029/2009JD013689.

Shen, L., L. J. Mickley, and A. P. K. Tai, 2015: Influence of synoptic patterns on surface ozone variability over the eastern United States from 1980 to 2012. Atmos. Chem. Phys., 15, 10925 10 938, https://doi.org/10.5194/acp-15-10925-2015.

Simon, H., A. Reff, B. Wells, J. Xing, and N. Frank, 2015: Ozone trends across the United States over a period of decreasing $\mathrm{NO}_{x}$ and VOC emissions. Environ. Sci. Technol., 49, 186-195, https://doi.org/10.1021/es504514z.

Skamarock, W. C., and J. B. Klemp, 2008: A time-split nonhydrostatic atmospheric model for weather research and forecasting applications. J. Comput. Phys., 227, 3465-3485, https://doi.org/10.1016/j.jcp.2007.01.037. 
Souri, A. H., Y. Choi, X. Li, A. Kotsakis, and X. Jiang, 2016a: A 15-year climatology of wind pattern impacts on surface ozone in Houston, Texas. Atmos. Res., 174-175, 124-134, https://doi.org/10.1016/j.atmosres.2016.02.007.

, - W. B. Jeon, X. S. Li, S. Pan, L. J. Diao, and D. A. Westenbarger, 2016b: Constraining $\mathrm{NO}_{x}$ emissions using satellite $\mathrm{NO}_{2}$ measurements during 2013 DISCOVER-AQ Texas campaign. Atmos. Environ., 131, 371-381, https://doi.org/10.1016/ j.atmosenv.2016.02.020.

Stauffer, R. M., A. M. Thompson, and G. S. Young, 2016: Tropospheric ozonesonde profiles at long-term U.S. monitoring sites: 1. A climatology based on self-organizing maps. J. Geophys. Res. Atmos., 121, 1320-1339, https://doi.org/10.1002/2015JD023641.

Stein, A. F., R. R. Draxler, G. D. Rolph, B. J. B. Stunder, M. D. Cohen, and F. Ngan, 2015: NOAA's HYSPLIT atmospheric transport and dispersion modeling system. Bull. Amer. Meteor. Soc., 96, 2059-2077, https://doi.org/10.1175/BAMS-D-14-00110.1.

Suciu, L. G., R. J. Griffin, and C. A. Masiello, 2017: Regional background $\mathrm{O}_{3}$ and $\mathrm{NO}_{x}$ in the Houston-Galveston-Brazoria (TX) region: A decadal-scale perspective. Atmos. Chem. Phys., 17, 6565-6581, https://doi.org/10.5194/acp-17-6565-2017.
Travis, K. R., and Coauthors, 2016: Why do models overestimate surface ozone in the southeast United States? Atmos. Chem. Phys., 16, 13 561-13 577, https://doi.org/10.5194/acp-1613561-2016.

Vesanto, J., J. Himberg, E. Alhoniemi, and J. Parhankangas, 2000: SOM toolbox for Matlab 5. Helsinki University of Technology, http://www.cis.hut.fi/projects/somtoolbox/.

Wang, Y. X., B. X. Jia, S. C. Wang, M. Estes, L. Shen, and Y. Y. Xie, 2016: Influence of the Bermuda high on interannual variability of summertime ozone in the Houston-Galveston-Brazoria region. Atmos. Chem. Phys., 16, 15 265-15276, https://doi.org/ 10.5194/acp-16-15265-2016.

Wiedinmyer, C., S. K. Akagi, R. J. Yokelson, L. K. Emmons, J. A. Al-Saadi, J. J. Orlando, and A. J. Soja, 2011: The Fire Inventory from NCAR (FINN): A high resolution global model to estimate the emissions from open burning. Geosci. Model Dev., 4, 625-641, https://doi.org/10.5194/gmd-4625-2011.

Zhu, J., and X. Z. Liang, 2013: Impacts of the Bermuda high on regional climate and ozone over the United States. J. Climate, 26, 1018-1032, https://doi.org/10.1175/JCLI-D-12-00168.1. 